\title{
Assessment on Bonding Potentials of Trackless Tack under a Thin Overlay
}

\author{
Ah Young Seo ${ }^{1, *}$, Maryam S. Sakhaeifar ${ }^{2}$ and Bryan T. Wilson ${ }^{3}$ \\ 1 Street \& Bridge Division, Austin, TX 78744, USA \\ 2 Zachry Department of Civil Engineering, Texas A\&M University, College Station, TX 77843, USA; \\ msakhaeifar@tamu.edu \\ 3 Texas A\&M Transportation Institute, College Station, TX 77843, USA; b-wilson@tti.tamu.edu \\ * Correspondence: ahyoung.seo@austintexas.gov
}

Citation: Seo, A.Y.; Sakhaeifar, M.S.; Wilson, B.T. Assessment on Bonding Potentials of Trackless Tack under a Thin Overlay. Infrastructures 2021, 6, 126. https://doi.org/10.3390/ infrastructures6090126

Academic Editor: Giuseppe Cantisani

Received: 24 June 2021

Accepted: 12 August 2021

Published: 3 September 2021

Publisher's Note: MDPI stays neutral with regard to jurisdictional claims in published maps and institutional affiliations.

Copyright: (c) 2021 by the authors. Licensee MDPI, Basel, Switzerland. This article is an open access article distributed under the terms and conditions of the Creative Commons Attribution (CC BY) license (https:// creativecommons.org/licenses/by/ $4.0 /)$.

\begin{abstract}
Trackless tacks are used to minimize the loss of tack materials caused by adherence to moving tires. During the last two decades, the paving industry and highway agencies have had an increasing interest in the use of trackless tacks to ensure an adequate bond between the overlay and the existing pavement. Therefore, the need for more studies on the bonding characteristics of various trackless tacks is growing. The purpose of this study is to measure the bonding potential of trackless tacks and identify several variables that affect the shear resistance in terms of bonding strength and energy using statistical analysis. The improvement of interlayer shear resistance by tack treatment is different depending on the tack and surface types. Higher tack reactivation temperatures increase the interlayer shear resistance. Compaction effort is considered to have only a marginal effect on bond performance. Tack and surface types play a more critical role in determining the shear bond strength than residual tack rate in the field experiment.
\end{abstract}

Keywords: thin overlay; interface bond; trackless tack; interlayer shear resistance; direct shear test

\section{Introduction \\ 1.1. Research Motivation}

A strong interfacial bond between a thin overlay and underlying layer is one of the key factors required for achieving the desired service life of a pavement. The thin overlay has been treated as a popular and useful practice for pavement rehabilitation in transportation agencies [1]; however, some U.S. state agencies reported distresses such as delamination and slippage in overlaid pavements [2-4]. A major contribution to the premature failure in the overlay is the quality of interface bonding [5-7]. Poor bonding increases a shear stress level around an interface [8] and the occurrence of the maximum stresses near the interface can lead to the development of interface debonding and pavement distress [9]. Pavement deterioration caused by insufficient bonding leads to a reduction in pavement life [10]. Roffe and Chaignon [11] found that an unbonded layers caused a $60 \%$ loss of its life. Brown and Brunton [12] estimated the life reduction by $70-75 \%$ for a debonded or poorly bonded pavement. In addition, these issues increase maintenance costs and adversely impact pavement sustainability [13]. Therefore, the bonding quality of tack coats at the interface should be evaluated to enhance the performance and sustainability of a rehabilitated pavement.

To ensure a sufficient bond between layers, a tack material should remain intact after tack application. However, a conventional tack coat is likely to track under paving equipment and passing vehicles. Although the tack coat is appropriately spread, the tack is lost in a wheel path due to its tracking by the vehicle tires. The loss of the tack material is expected to provide no improvement of bonding within the tracked area. Unlike the traditional tack, a newly specialized tack product, the trackless tack, tends to be hardened quickly and to stick minimally to the vehicle tires. The recent studies of Seo et al. [14] and 
$\mathrm{Lv}$ and Bahia [15] showed the measurement on the tracking resistance of various trackless tacks and successfully evaluated the critical factors that affect their tracking property.

Many U.S. highway agencies and paving industries have recently had an increasing interest in the use of trackless tacks for a well-bonded interface; nonetheless, very few studies on the interlayer bonding of trackless tacks have been conducted as compared to conventional tacks. Moreover, there has been no specification or test procedure for new tack products from the Texas Department of Transportation (TxDOT). Hence, further examination of the bonding performance of the trackless tacks is needed for proper selection and application of tack coats.

\subsection{Objective and Methodology}

The objective of this paper is to measure the bond potential of trackless tack coats in bonded pavement layers. First, the tacks were characterized in terms of the rheological properties using a frequency sweep test. Then, laboratory compacted mixture and /or field cores applied with tacks were tested using a direct shear test. The effect of several factors on shear bonds in strength and energy was investigated using laboratory compacted mixtures. These factors include tack type, substrate type, compaction effort, and reactivation temperature. The effect of tack application rate, tack type, and surface type of an underlying layer on the interface shear resistance was identified using field cores. Finally, a statistical analysis was conducted to determine the critical variables that influence shear bonds.

\section{Literature Review}

Many previous studies have tested the laboratory or field compacted samples in different loading modes to evaluate the interlayer bond. Among bonding tests, the shear tests are widely used due to the simplicity of test procedure and similarity of the failure mechanism to slippage [16]. The research team at the National Center for Asphalt Technology [17] developed the Shear NCAT Bond Strength Device and recommended a minimum strength of $689 \mathrm{kPa}$ [18]. This recommendation was subsequently lowered to $552 \mathrm{kPa}$. Other devices with a similar setup include the layer-parallel direct shear test [19] and a shear test from the Virginia Transportation Research Council [20].

In several shear tests, a normal load is simultaneously applied to consider a realistic loading condition. These tests include a direct shear box originally designed by Uzan et al. [21], the Ancona shear testing research and analysis (ASTRA) device developed by Santagata and Canestrari [22], and the Louisiana interlayer shear strength tester (LISST) built later by Mohammad et al. [3]. The recent study of Mohammad et al. [3] observed that there is no significant difference in shear strength between the Superpave shear tester (SST) that applies only shear load and the LISST when dilation is not restricted in the SST. In addition, the minimum bond strength of $276 \mathrm{kPa}$ was suggested.

Unlike other studies that focused on measuring the bond strength, Romanoschi and Metcalf [23] determined the shear fatigue resistance at the interface using the shear fatigue test that allows for the repetitive application of both normal and shear loading types. The results showed that the presence of a tack coat at the interface prolongs the fatigue life. Another study by Hakimzadeh et al. [24] quantified fracture energy using the interface bond test (IBT). The IBT device controls the crack mouth opening displacement (CMOD) on the front of the notch located along the interface. The results from the IBT test showed a similar trend to those from a direct tension test. It was found that polymer-modified emulsion provides stronger bonds than conventional tack and the fracture energy of samples tested at $-20{ }^{\circ} \mathrm{C}$ was higher with the increase in the tack application rate up to $0.9 \mathrm{~L} / \mathrm{m}^{2}\left(0.2 \mathrm{gal} / \mathrm{yd}^{2}\right)$.

Different factors affecting the bond strength at the interface where tack coats are applied have been investigated by different researchers [3,18,20,25-31]. The factors in most of these studies are tack coat type, surface type, mixture type, temperature, and residual tack rate. The findings of these studies are that surface roughness has a high impact on the interface shear strength and surface milling provides a remarkable increase 
in shear strength. It was also observed that higher temperature lowers the interface shear strength and the effect of tack type on shear bond strength is different depending on the mixture type. However, different observations were reported on the tack application rate. The results of the study conducted by McGhee and Clark [20] showed no effect of tack application rate on shear strength. West et al. [18] reported an inverse relationship between application rate and shear strength for fine-graded mixtures, while no relation was observed for coarse-graded mixtures. Amelian and Kim [29] suggested that the excessive application rate of a tack coat may have a negative impact on the bonding at the interface due to the formation of a slippage plane in the lubricant layer of the tack coat. Mohammad et al. [3] concluded that higher application rates lower th shear bond strength in laboratory compacted samples, whereas the opposite result was observed in field cores. In the study conducted by Al-Qadi et al. [25], the optimum tack coat application rate was recommended depending on surface type, tack coat type, and cleanliness. Zhao et al. [28] reported that tack coat application rate and mixture type are less important factors that influence the interlayer shear strength as compared to the surface texture on a cement concrete slab, the tack type, temperature, and humidity.

With respect to the performance of trackless tacks, most studies [3,20,32,33] proved that trackless tacks provide higher shear strength than conventional tack coats. McGhee and Clark [20], on the contrary, showed that the bond strength of conventional tack coats in both shear and tensile modes is higher than that of trackless tack material, albeit in a limited test scope. Chen et al. [32] also found that a top-down cracking resistance decreases with thr increasing brittleness of trackless tacks. As such, a few areas of these materials still need to be improved. This study conducted a comprehensive laboratory and field investigation of trackless tack materials.

\section{Materials and Methods}

\subsection{Materials}

The material type in each layer of the asphalt mixture is presented in Table 1. The hot mix asphalt (HMA) overlay and substrate layer are composed of Type $C$ and D mixtures, respectively, which are widely used in Texas for resurfacing existing pavements. The Type $\mathrm{C}$ mixture has a coarse surface with $19 \mathrm{~mm}$ nominal maximum aggregate size (NMAS), whereas the Type D mixture has a fine surface with $12.5 \mathrm{~mm}$ NMAS. The gradation of both mixtures meets the TxDOT specification indicated in Figure 1. The selected asphalt binder and theoretical maximum specific gravity are PG 76-22 and 2.391 for the upper layer, and PG 64-22 and 2.422 for the lower layer. The tack coat materials used in this study include one conventional tack and five different trackless tacks. The control tack, CSS- $1 \mathrm{H}$, is a traditional cationic emulsion that consists of a hard asphalt with slow-setting and low viscosity. The trackless tacks include two cationic emulsified binders (CQS-1HT and $\mathrm{CBC}-1 \mathrm{H}$ ), two anionic emulsions (NTQS-1HH and QS-1HH), and a polymer-modified binder, and were randomly labelled into Tack $\mathrm{A}$ to $\mathrm{E}$ for anonymity.

Table 1. Material types used in the mixture layers.

\begin{tabular}{cc}
\hline Layer & Material Type \\
\hline Overlay & Thin overlay mixture (TOM) Type C \\
Substrate & Superpave mixture Type D \\
Tack coat & 1 control tack (CSS-1H), 5 trackless tacks ${ }^{1}$ (NTQS-1HH, \\
& CQS-1HT, QS-1HH, CBC-1H, and polymer-modified binder) \\
\hline
\end{tabular}

${ }^{1}$ Trackless tack labels are randomly assigned into Tack $\mathrm{A}$ to $\mathrm{E}$ for anonymity.

\subsection{Experimental Plan}

This study focuses on the characterization of trackless tack materials for rheology and interlayer shear resistance. A series of dominant factors on shear bonding were evaluated. The testing plan for interlayer shear resistance is presented in Table 2. 


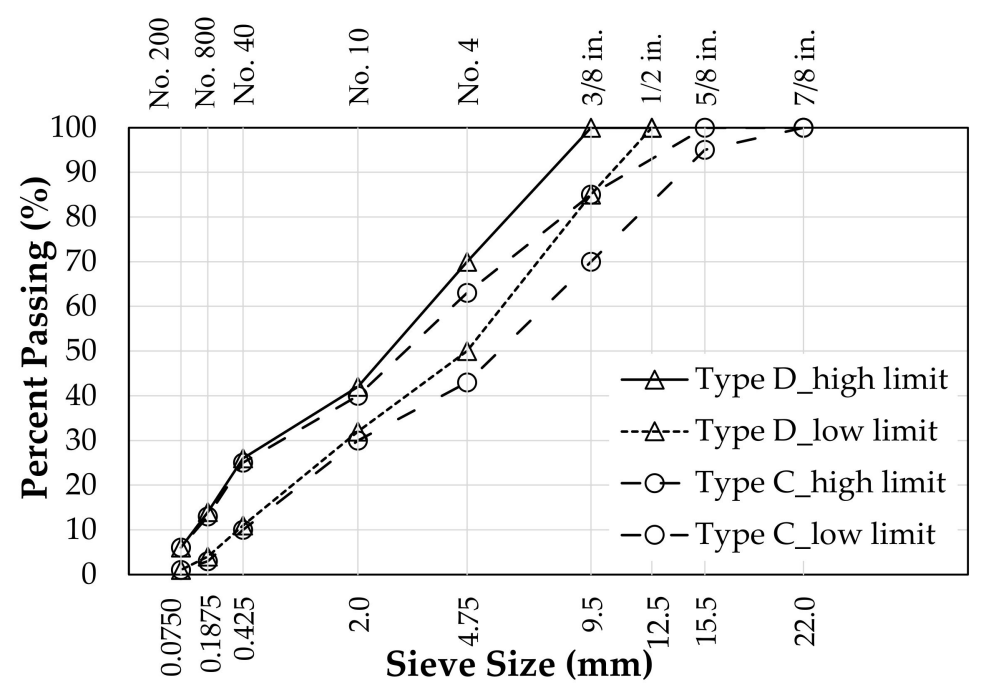

Figure 1. TxDOT specifications for Type $C$ and D mixtures.

Table 2. Test factorial for interlayer shear resistance.

\begin{tabular}{|c|c|c|c|}
\hline Sample & Variable $^{1}$ & Values & Number of Values \\
\hline \multirow{5}{*}{$\begin{array}{l}\text { Laboratory } \\
\text { compacted } \\
\text { samples }\end{array}$} & Tack & $\begin{array}{c}\text { No Tack, Control Tack, Tack A, } \\
\text { Tack B, Tack C, Tack D, and } \\
\text { Tack E }\end{array}$ & 7 \\
\hline & Substrate & $\begin{array}{l}\text { Severely polished HMA, } \\
\text { mildly polished HMA, and } \\
\text { Portland cement concrete }\end{array}$ & 3 \\
\hline & \multirow{2}{*}{$\begin{array}{l}\text { Tack reactivation } \\
\text { temperature }\left({ }^{\circ} \mathrm{C}\right)\end{array}$} & 135,149 (overlay) & 2 \\
\hline & & $15,25,40$ (substrate) & 3 \\
\hline & Compaction angle $\left(^{\circ}\right)$ & $1,1.25$ & 2 \\
\hline \multirow{3}{*}{ Field cores } & Tack & No Tack, Tack B, and Tack D & 3 \\
\hline & Surface condition & Existing, new, milled & 3 \\
\hline & Residual tack rate & $\begin{array}{l}\text { Low }^{2}\left(0.05-0.14 \mathrm{~L} / \mathrm{m}^{2}\right) \\
\text { moderate }\left(0.14-0.23 \mathrm{~L} / \mathrm{m}^{2}\right), \\
\text { and high }\left(0.23-0.32 \mathrm{~L} / \mathrm{m}^{2}\right)\end{array}$ & 3 \\
\hline
\end{tabular}

${ }^{1}$ Some variables were not fully evaluated in the test factorial. ${ }^{2}$ Low rate was omitted in the milled section.

The laboratory test plan consists of small-scale experiments that consider the tack type, substrate type, compaction effort, and tack reactivation temperature of overlay and substrate layers. The samples with tack materials as well as no tack treatment were tested to identify the effect of tack type on shear bonding at the interface. To investigate the effect of substrate type on shear bonds, three substrates including severely polished HMA, mildly polished HMA, and Portland cement concrete (PCC) were used. The severely polished HMA substrate was conditioned with coarse (80-grit) and fine (220-grit) sandpapers attached to an orbital sander, whereas the mildly polished substrate was treated only with coarse grit sandpaper in the laboratory. In addition, the compaction angle of $1^{\circ}$ and $1.25^{\circ}$ was chosen to determine the impact of the compaction effort on interlayer shear resistance. To evaluate the effect of tack reactivation temperature, the substrates with cured tack were conditioned at 15,25 , and $40^{\circ} \mathrm{C}$, and overlay mixtures were compacted at 135 and $149^{\circ} \mathrm{C}$.

The field testing plan examined the effect of surface condition, tack type, and residual tack rate on shear bonds. The effect of surface condition was assessed through a thin overlay construction project on US 183 in Cedar Park between Osage Drive and FM 1431. This site involves three test sections: existing HMA, new HMA, and milled sections. The existing HMA surface was significantly polished by climate and traffic exposure over the 
years as depicted in Figure 2a. The pavement in most parts of the milled section was uniformly milled as depicted in Figure 2b; however, inconsistent milling was found in some areas of this section as depicted in Figure 2c.

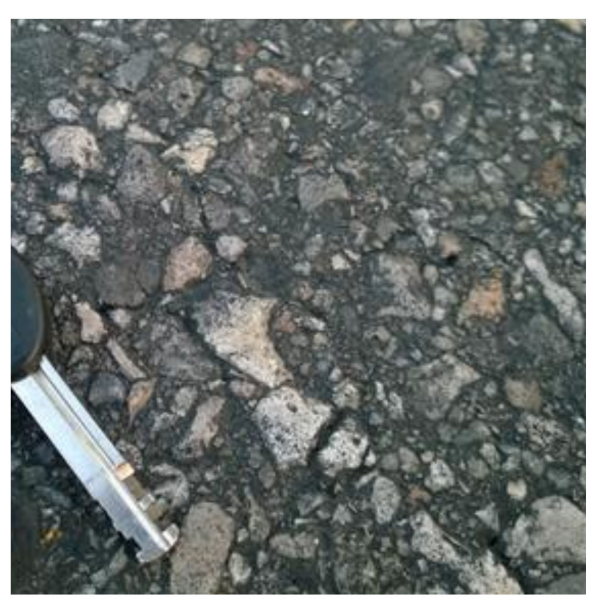

(a)

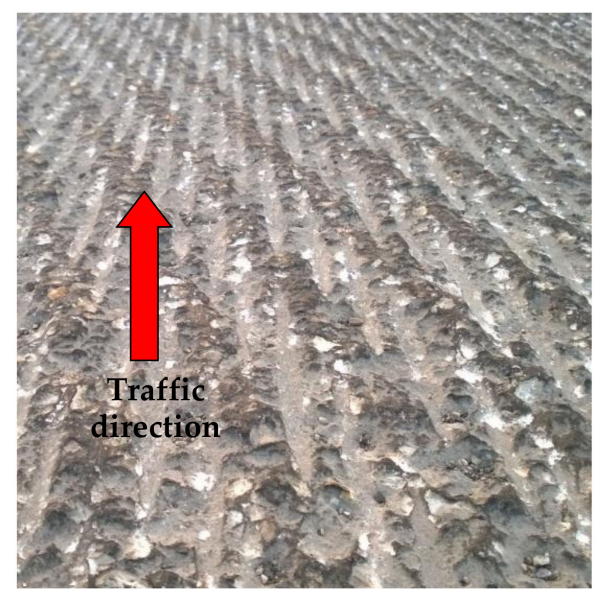

(b)

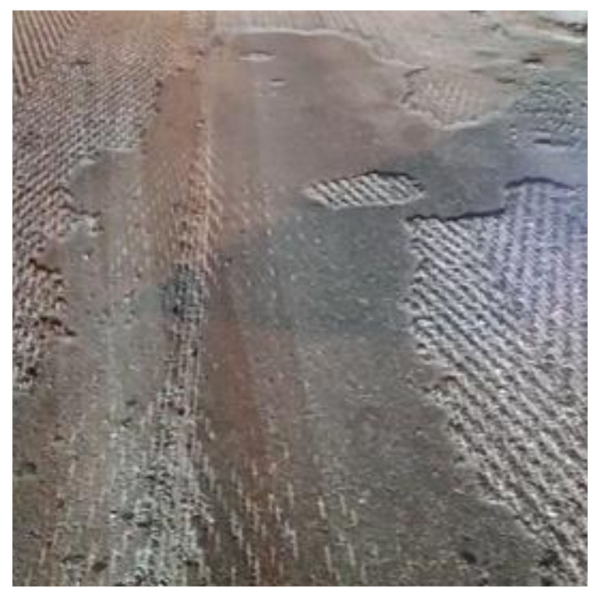

(c)

Figure 2. Surface conditions of US 183 field project including: (a) existing; (b) uniformly milled; and (c) scabbed-milled surfaces.

Two trackless tacks (Tack B and D) were used in the field. The three application rates used are $0.18,0.32$, and $0.45 \mathrm{~L} / \mathrm{m}^{2}\left(0.04,0.07\right.$, and $\left.0.1 \mathrm{gal} / \mathrm{yd}^{2}\right)$, in addition to no tack application rate. The residual tack rates were measured as specified in ASTM D2995. In several sections, the residual rates were estimated on the basis of measurements from similar sections. The approximate values of residual tack rates are 0.05 to $0.14 \mathrm{~L} / \mathrm{m}^{2}$ ( 0.01 to $\left.0.03 \mathrm{gal} / \mathrm{yd}^{2}\right)$ in the low level, 0.14 to $0.23 \mathrm{~L} / \mathrm{m}^{2}\left(0.03\right.$ to $\left.0.05 \mathrm{gal} / \mathrm{yd}^{2}\right)$ in the moderate level, and 0.23 to $0.32 \mathrm{~L} / \mathrm{m}^{2}\left(0.05\right.$ to $\left.0.07 \mathrm{gal} / \mathrm{yd}^{2}\right)$ in the high level. It should be noted that the low tack application rate was omitted on the milled surface for all tacks used in the project. This was done considering the low tack rate could not fully cover the surface due to high roughness in the milled sections. Three replicates for each variable were used in the laboratory and field testing plan but the field samples with the poorly milled surface shown after testing were excluded in the data analysis to minimize the impact of milling quality.

\subsection{Sample Preparation and Test Procedure}

The frequency sweep test was run to identify the rheological properties of tack residual binders. The water in the tack emulsion was eliminated through the low evaporative technique specified in AASHTO PP72 Method B to obtain the residual binder. As the first step, the emulsion sample was stirred well and spread on a silicon mat. A thin film applicator and a wet film thickness gauge were used to achieve the desired thickness of $0.38 \mathrm{~mm}$. After a thin layer of emulsion on the silicon mat was cured in an oven at $60^{\circ} \mathrm{C}$ for $6 \mathrm{~h}$, the residue was peeled carefully and kept in a cool storage. The binder samples were tested at different loading frequencies ( 0.1 to $100 \mathrm{rad} / \mathrm{s})$ and seven temperatures $\left(6,10,22,34,46,58\right.$, and $\left.70^{\circ} \mathrm{C}\right)$. The strain level of $0.1 \%$ and $1 \%$ was selected for the first four temperatures and the last three temperatures, respectively. These values are below the linear viscoelastic (LVE) strain limit, specified by Petersen et al. [34]. To create the master curves of the complex shear modulus and phase angle, the reference temperature of $20^{\circ} \mathrm{C}$ was chosen.

In the next test, the interlayer shear resistance of laboratory compacted samples and field cores was evaluated using a direct shear test. In preparation of laboratory compacted specimens, a loose mixture was collected from a production plant. Through a preliminary test run with different gyrations, it was found that higher gyration levels dramatically strengthened the interface bond and consequently increased the chances of failing within 
the overlay mixture. To maximize the occurrence of interface failure in the bonding test, the number of gyrations for the HMA substrate and overlay mixture was determined to be 60 and 25 gyrations, respectively. After samples were compacted using the Superpave gyratory compactor, the substrate mixtures were polished and air-dried. Heated tack was manually applied onto the substrate surface with a paint brush and the recommended tack residual rate by the vendor was used. The samples were cured in an oven at $60^{\circ} \mathrm{C}$ for 30 to $60 \mathrm{~min}$ and then placed in another oven set at the specified substrate temperature. As the last step, the overlay mixture was compacted on the substrate.

The field samples of all projects were cored in the center of the lane, not along the wheel path, to eliminate the tracking effect of field results. The direction of traffic was marked on all samples in the milled section so that loads were applied at the laboratory in the same direction as marked. The samples were allowed to be fully dried before testing.

The direct test requires the interface shear test apparatus, as presented in Figure 3, which consists of one side holding a specimen rigidly and a free-sliding side moving vertically. For samples with a smaller diameter than the device, core shims were inserted to align samples within the device during the testing. The specimens were tested at a rate of $5 \mathrm{~mm} / \mathrm{min}$ until failure at the ambient temperature.

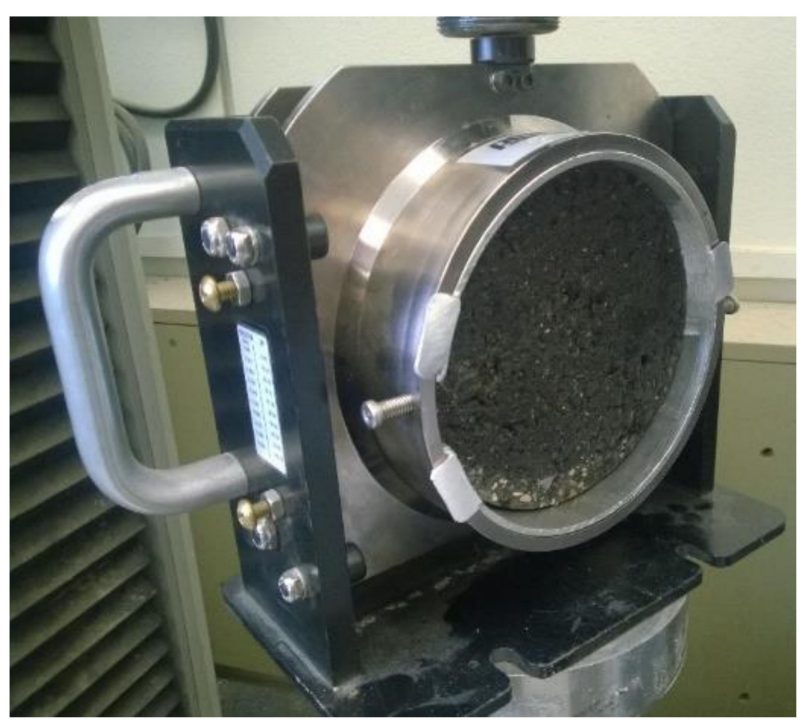

Figure 3. Test apparatus of interface shear test.

In this study, both shear bond strength and energy were measured to evaluate the interlayer shear resistance. The research conducted by Amelian and Kim [29] confirmed that the energy term can be an important indicator of fatigue resistance in the shear mode. It was indicated that shear energy until a peak load has a higher correlation with the results of the cyclic shear test than the results of the shear strength test. In this study, hence, the shear bond strength was determined from the peak load and the shear bond energy was calculated to be the area under the load displacement curve up to the peak load per unit of the initial cross-sectional area of the samples. The failure location was recorded to identify if a failure mainly occurs at the interface or within adjacent layers. The sensitivity of different variables to the bonding potential was evaluated with an analysis of variance (ANOVA) test. The selected $p$-value in the ANOVA test is 0.05 to determine the critical factors affecting the interlayer shear resistance.

\section{Results and Discussion}

\subsection{Rheological Properties}

The master curves of the complex shear modulus and phase angle for all tack residues are shown in Figure 4. The test results show that the control tack was the softest and least viscous material among all the tested samples, followed by Tack A, B, and C, in 
that order. Tack A and B residues exhibited similar stiffness over the tested frequency range. Tack $\mathrm{D}$ and $\mathrm{E}$ had higher stiffness and showed a breakdown of the mater curve of the complex shear modulus at a low frequency. In this region, the accuracy of the timetemperature superposition principle may be affected when structural changes occur at high temperatures for highly structured asphalts such as the ones with high asphaltene content, high crystallized fractions, or polymer modification $[35,36]$. The polymer modification also contributes to increasing the high-temperature stiffness of modified asphalt binders [37]. As a result, control tack, Tack A, B, and C were classified in a soft-residue group, whereas Tack $\mathrm{D}$ and $\mathrm{E}$ were in a stiff-residue group.

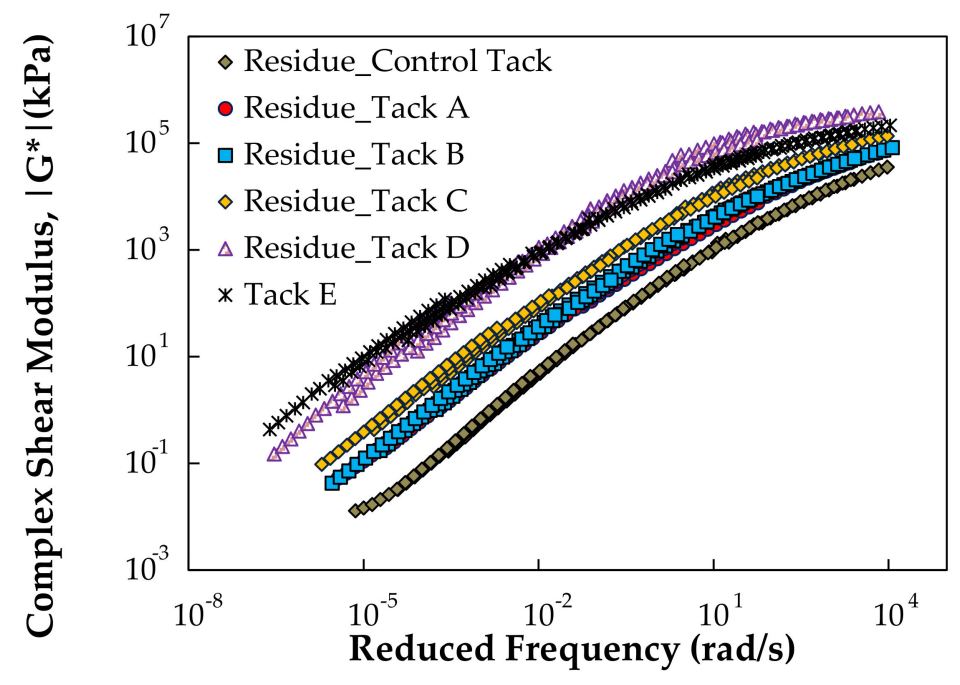

(a)

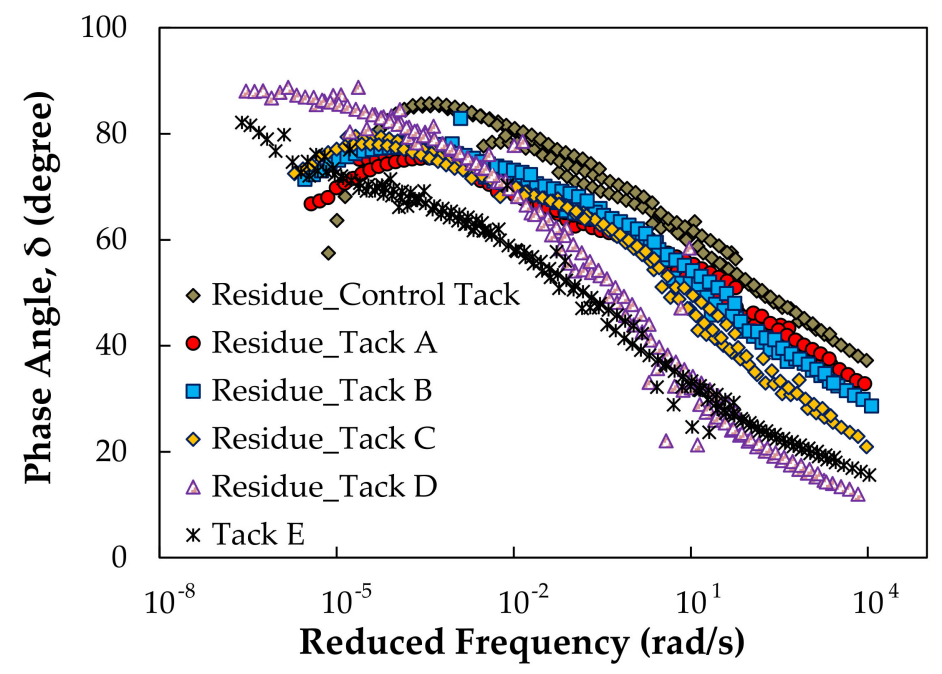

(b)

Figure 4. DSR frequency sweep test results for the residue of tack materials: (a) complex shear modulus and (b) phase angle master curves.

\subsection{Shear Bonding Potential of Laboratory Samples \\ 4.2.1. Tack Type}

Figures 5 and 6 display the results of the direct shear test on laboratory compacted samples for the effect of tack type on shear bonds. As can be observed in Figure 5a, there was no significant difference in the shear bond strength of tack samples. The shear bond strength of the No Tack sample was slightly lower than that of other samples. However, all samples including the No Tack sample had excellent bonds over $1000 \mathrm{kPa}$. This level is about $45 \%$ higher than the minimum strength of $689 \mathrm{kPa}$ as suggested by West et al. (2005). 
In Figure 5b, the No Tack sample exhibited lower shear bond energy than the other tack samples. Among the samples applied with tacks, the Tack B sample had the lowest shear bond energy, followed by tack samples in the soft-residue group, and the Tack E sample achieved the highest shear bond energy.

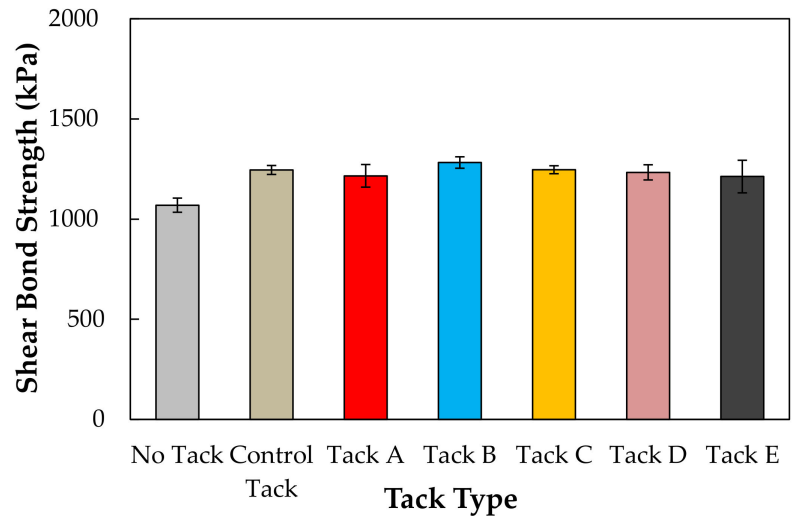

(a)

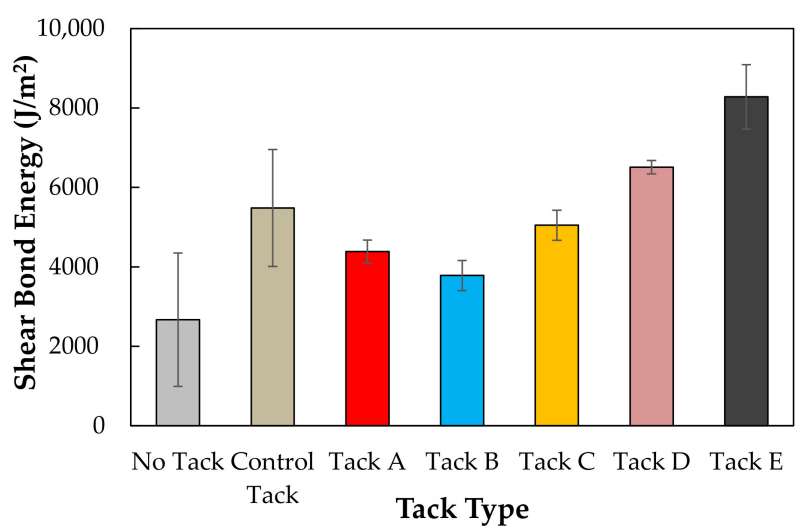

(b)

Figure 5. Effect of tack type on (a) shear strength and (b) shear bond energy for laboratory compacted samples.

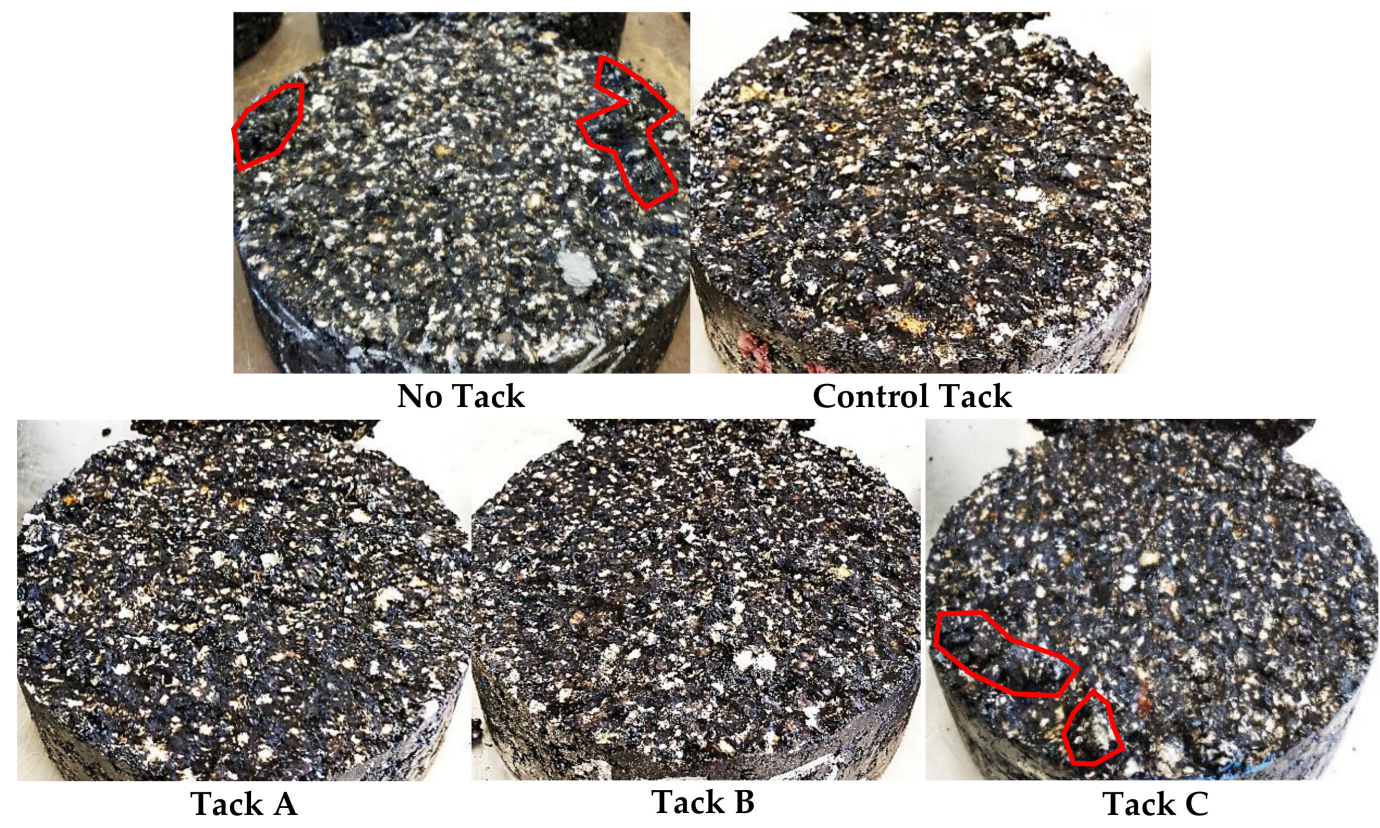

(a) Soft binder

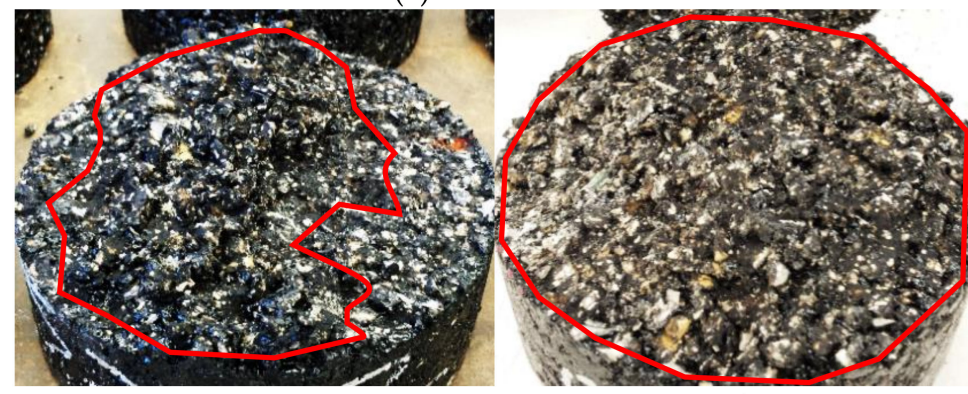

Tack D

Tack E

(b) Stiff binder

Figure 6. Failure location for laboratory compacted samples applied with different tacks: (a) soft binder and (b) stiff binder groups. Note: red marked areas indicate the failure through the overlay mixture. 
The difference in energy between samples having similar bond strengths was associated with a crack growth path. It is noted that the red marked areas indicate the failure through the overlay mixture. As seen in Figure 6a, the No Tack sample and tack samples in the soft-residue group were prone to fail at the interface, showing few fragments of the overlay mix at the edge of the substrates. This implies that tacks in the soft-residue group had a weak bond between the overlay and substrate layers. In contrast, the Tack D and E samples in the stiff-residue group mostly failed within the overlay, as highlighted with a red marker in Figure $6 \mathrm{~b}$. It indicates that the tacks had a stronger bond than the mix, thus the shear bond strength resulted from the mix. As the shear bond energy considers not only the peak force but also the displacement associated with crack growth [29], the energy term could quantify the interlayer shear resistance of tacks, especially for asphalt mixtures having a similar bond strength and different failure locations (i.e., along the interface or through the mix).

\subsubsection{Substrate Type}

Figures 7 and 8 show the results of the laboratory compacted samples with No tack and Tack D, indicating the influence of the substrate type on interlayer shear resistance. For samples without tack, the concrete substrate exhibited extremely low shear bond strength and energy than the HMA substrates, as shown in Figure 7a,b. In a comparison between two HMA substrates, polishing of the laboratory prepared HMA surfaces did not affect the shear bond strength and energy. The application of Tack D on the HMA and concrete substrates provided higher shear resistance in terms of strength and energy, and the improvement of bonding on the concrete substrate was significant.

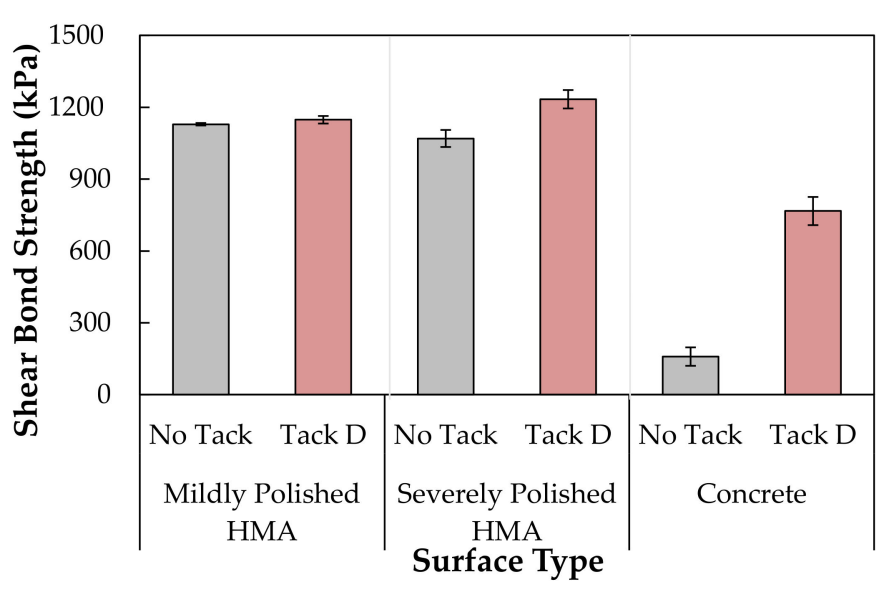

(a)

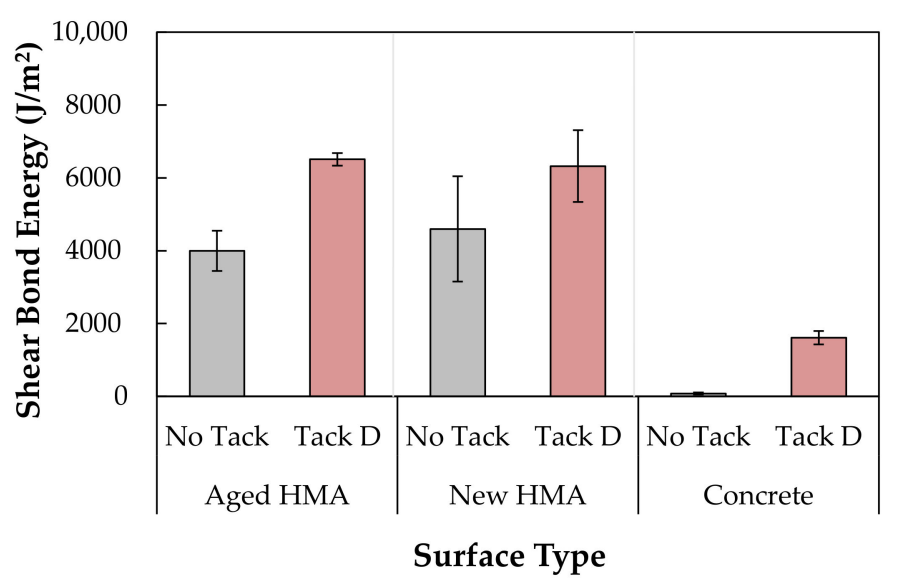

(b)

Figure 7. Effect of substrate type on (a) shear strength and (b) shear bond energy.

For the two HMA substrates presented in Figure 8a,b, an interface failure was dominant for No Tack samples, while many fragments of the overlay mix were shown in Tack D samples as marked in red. On the contrary, interface debonding occurred on the concrete substrate regardless of tack application, as shown in Figure 8c.

\subsubsection{Tack Reactivation Temperature}

The effect of tack reactivation temperature on interlayer shear resistance for laboratory samples with different tacks is presented in Figure 9. The tack reactivation temperature used in this study is defined as the average of the substrate temperature and the compaction temperature of the overlay mixture. At lower temperatures, all samples were broken at the interface. With the increase in temperature, a partial or complete failure in the mix was observed for four specimens (i.e., Tack D and E samples at $87^{\circ} \mathrm{C}$, and Tack C and D samples at $95^{\circ} \mathrm{C}$ ). Obviously, higher tack reactivation temperature increased the adhesion of tacks to adjacent layers, which resulted in higher shear bond strength and energy for all 
samples including the No Tack sample. At the tested temperature range, Tack E and No Tack samples exhibited the highest and lowest shear bond strength and energy, respectively. Tack $C$ had higher shear bond strength but lower shear bond energy than Tack D.

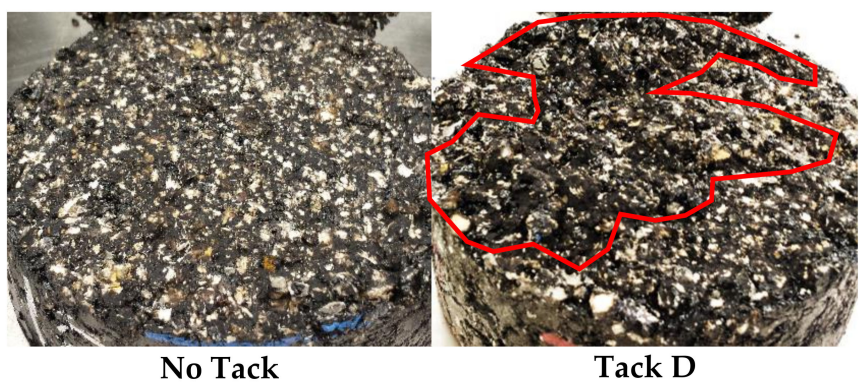

(a) Mildly Polished HMA

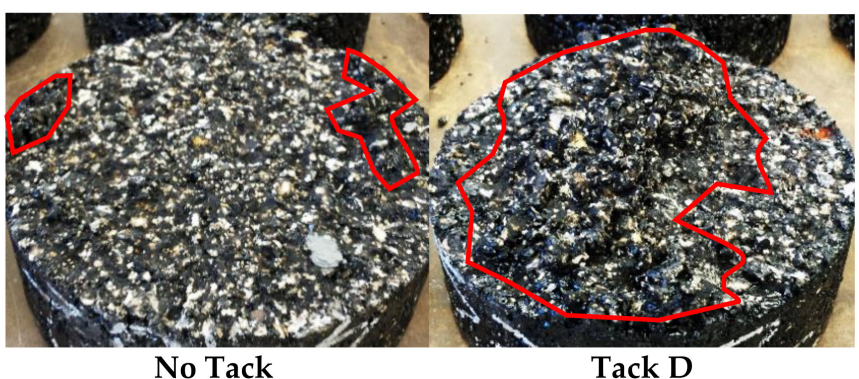

(b) Severely Polished HMA

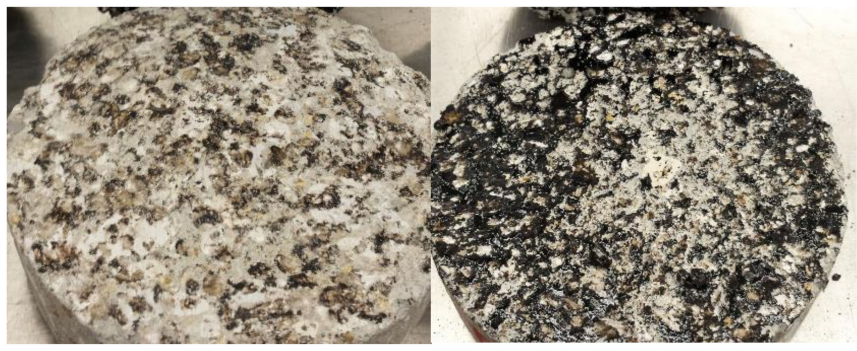

No Tack

Tack D

(c) Portland Cement Concrete

Figure 8. Shear failure of laboratory compacted samples applied without tack and with Tack D on different surfaces: (a) mildly polished HMA, (b) severely polished HMA, and (c) Portland cement concrete. Note: red marked areas indicate the failure through the overlay mixture.

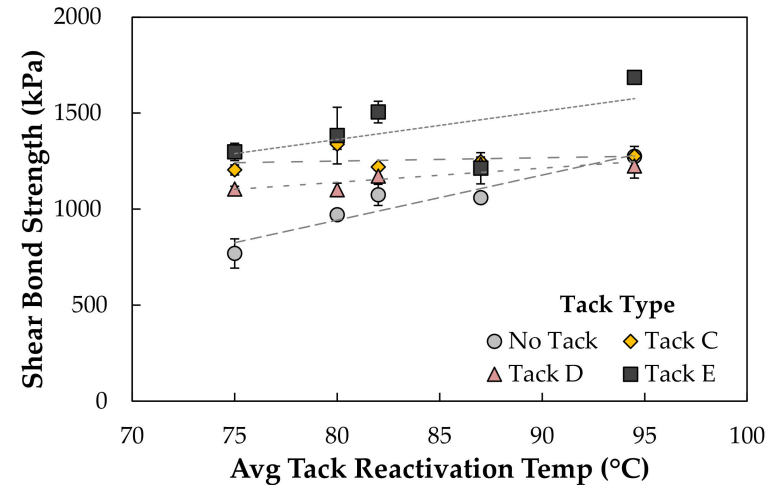

(a)

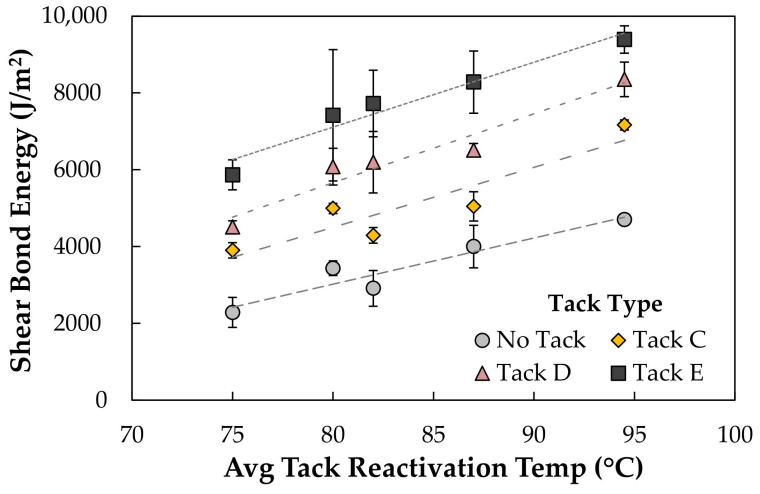

(b)

Figure 9. Effect of tack reactivation temperature on (a) shear bond strength and (b) shear bond energy for laboratory samples with different tacks. 


\subsubsection{Compaction Angle}

The last variable of interlayer shear resistance for laboratory compacted samples was the compaction angle. The shear bond strength and energy of No Tack and Tack D samples compacted at 1 and $1.25^{\circ}$ are presented in Figure 10. The effect of the compaction angle on bonding was less significant than that of tack application. Overall, higher compaction angles provided a $7.8 \%$ increase in strength and 9.3\% in energy. In addition, it was observed that an increase in compaction angle did not change the failure location, except for one testing condition. At the tack reactivation temperature of $95^{\circ} \mathrm{C}$, the higher compaction angle slightly lowered the occurrence of interface failure.

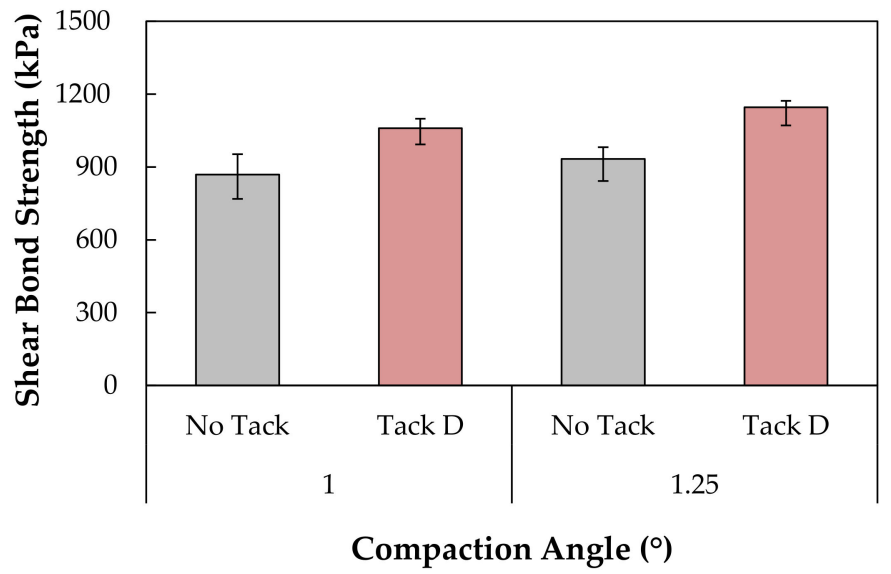

(a)

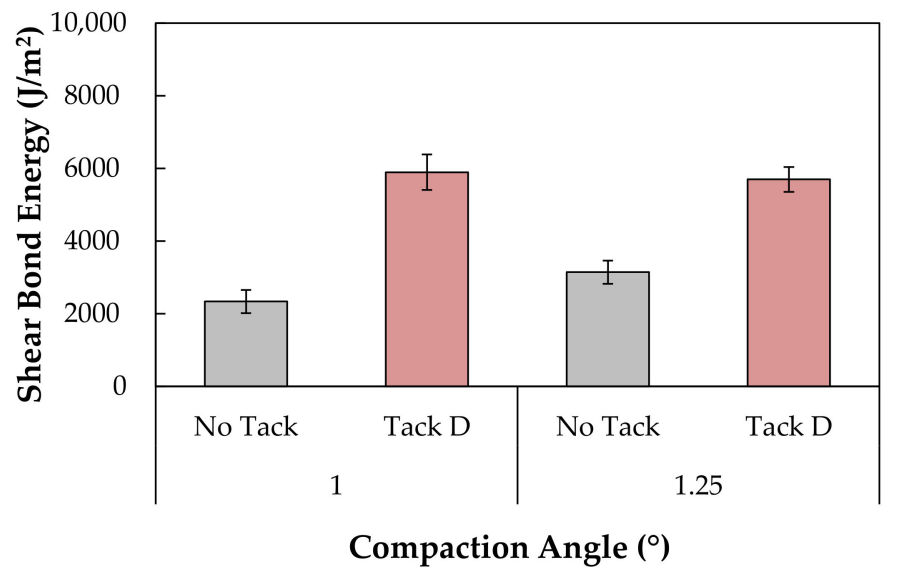

(b)

Figure 10. Effect of compaction angle on (a) shear bond strength and (b) shear bond energy.

\subsection{Shear Bonding Potential of Field Samples}

The results of the direct shear test for field cores are described in Figures 11 and 12. Figure 11 displays the fractured surface of field cores having different substrates. Unlike laboratory prepared specimens, all the field cores failed at the interface. It was challenging, if not impossible, to distinguish the failure mode, including cohesive and adhesive failures, during the test. As marked with a red marker in Figure 11a, the brighter surface area of the existing layer was uncovered by the tack material unevenly. Figure $11 \mathrm{~b}$ shows the new layer broken smoothly at the interface and the failure mode of the new layer was not definite. Figure 11c shows the interface failure of the milled layer having a wave pattern. Several bright lines on the ridge of the upper layer and the groove of the bottom layer were observed. During the milling process, fine particles were accumulated on the groove of the bottom layer and some of the particles were picked up to the ridge of the upper layer. The loss of adhesion along the bright lines lowers the interface shear resistance of the milled layer.

Figure 12 illustrates the shear bond strength of field cores to evaluate three factors (surface type, tack type, and residual tack rate) related to interface bonding. Here, the energy term was not considered in evaluating interlayer shear resistance because all the field samples failed at the interface. The field cores had considerably lower shear bond strength, of which the level was approximately $30 \%$ of the average strength of the laboratory compacted samples without tack treatment. The differences in shear bond strength and failure between the laboratory and field samples may be caused by fabrication methods such as compaction and tack application as well as substrate conditions. While the laboratory samples were covered with tacks using a paint brush and compacted using a gyratory compactor, the field samples were fabricated using a spray paver and a roller. Furthermore, the substrates of the laboratory samples were clean and unaged, whereas the field substrates were aged and contaminated with dirt and moisture. 


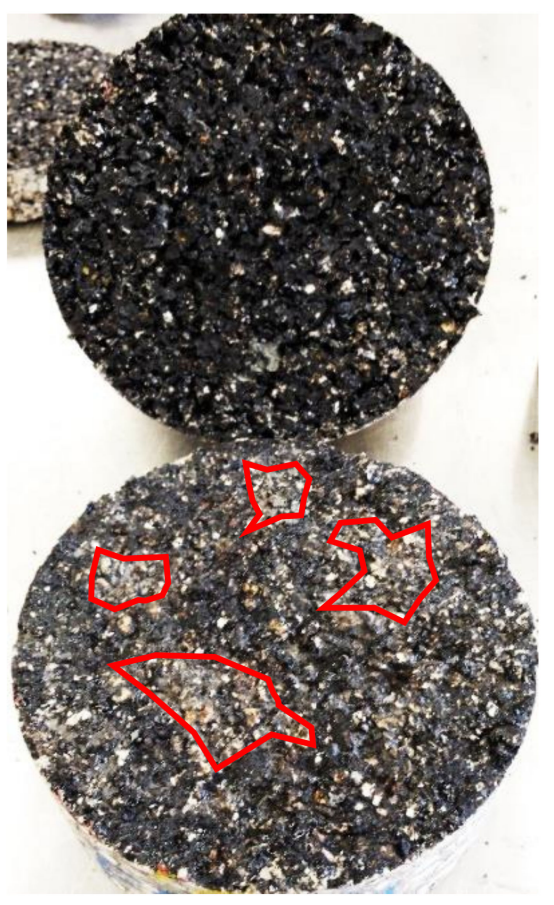

(a)

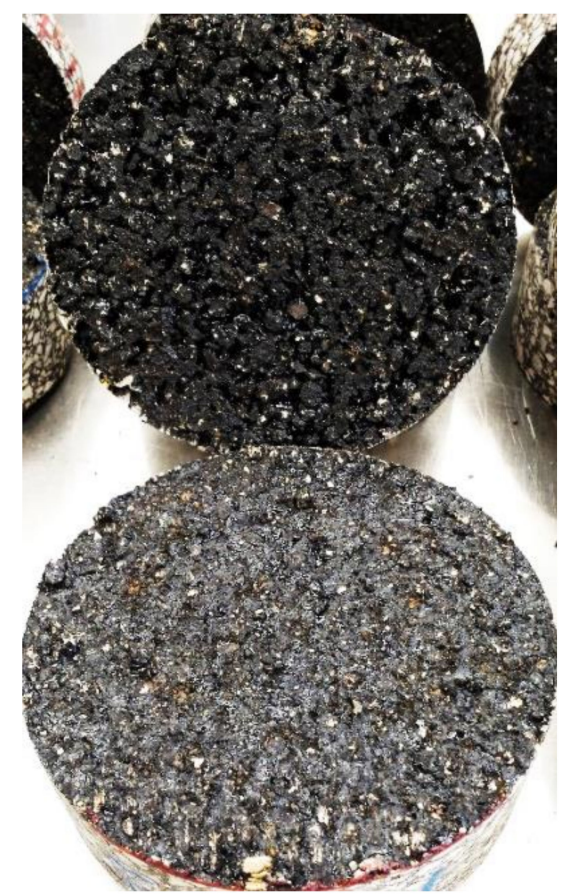

(b)

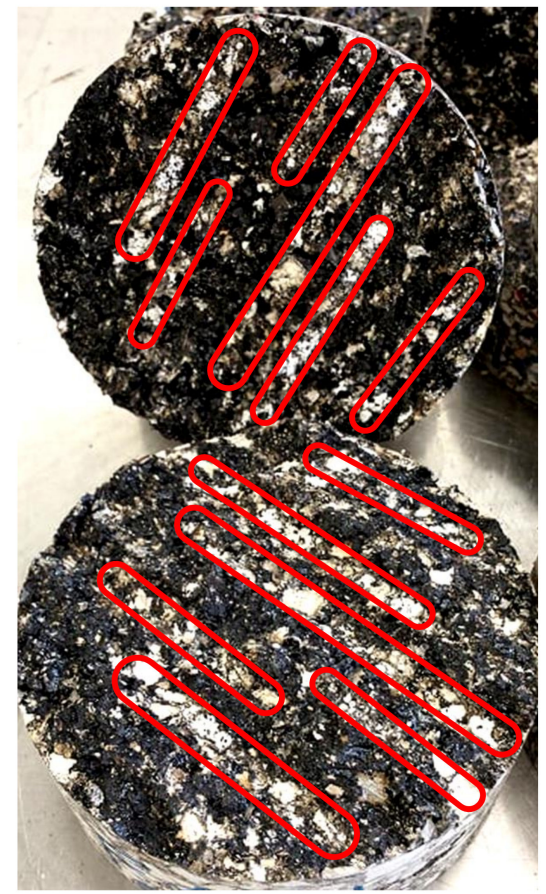

(c)

Figure 11. Interface shear failure of field cores having different underlying layers in: (a) existing, (b) new, and (c) milled sections. Note: red marked areas indicate adhesive failure between the tack coat and substrate surface.

On the existing surface, as presented in Figure 12a, the Tack B treatment did not produce a substantial increase in shear bond strength, whereas the Tack D treatment dramatically improved the interface bond. In addition, a moderate tack rate showed the highest bond strength, while a high rate had an adverse impact on the shear resistance. However, the interlayer shear resistance was less sensitive to different levels of the residual tack rate than the tack type.

On the new layer, as shown in Figure 12b, the application with either Tack B or D did not significantly improve the shear bond strength. Furthermore, the No Tack sample with the new substrate had higher bond strength than the one with the existing substrate. Considering the asphalt binder of the bottom layer was not severely aged, it is possible that the binders of the top and bottom layer at the interface adhered to each other without tack. For the tack samples having the new surface, the shear resistance was independent of tack quantity. The new layer had higher sample-to-sample variance than other layers.

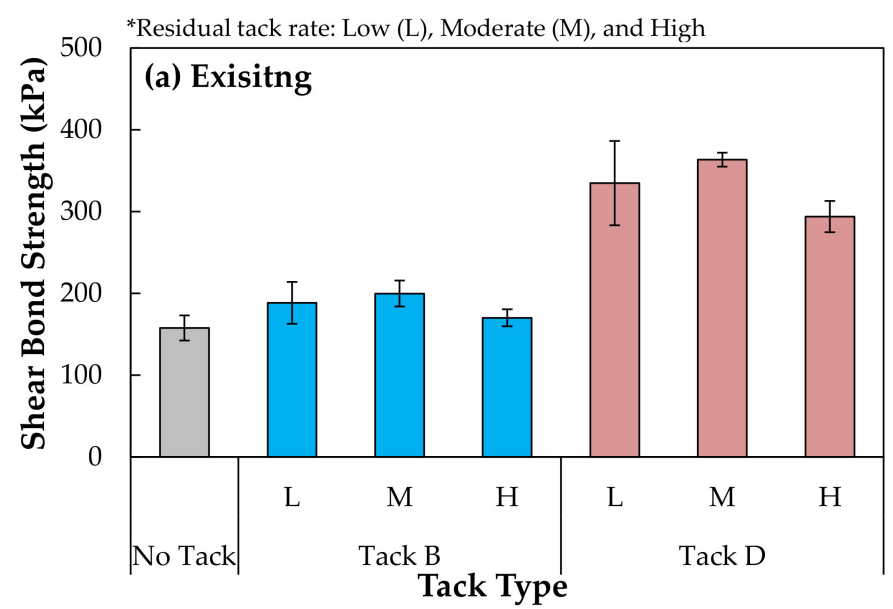

Figure 12. Cont. 

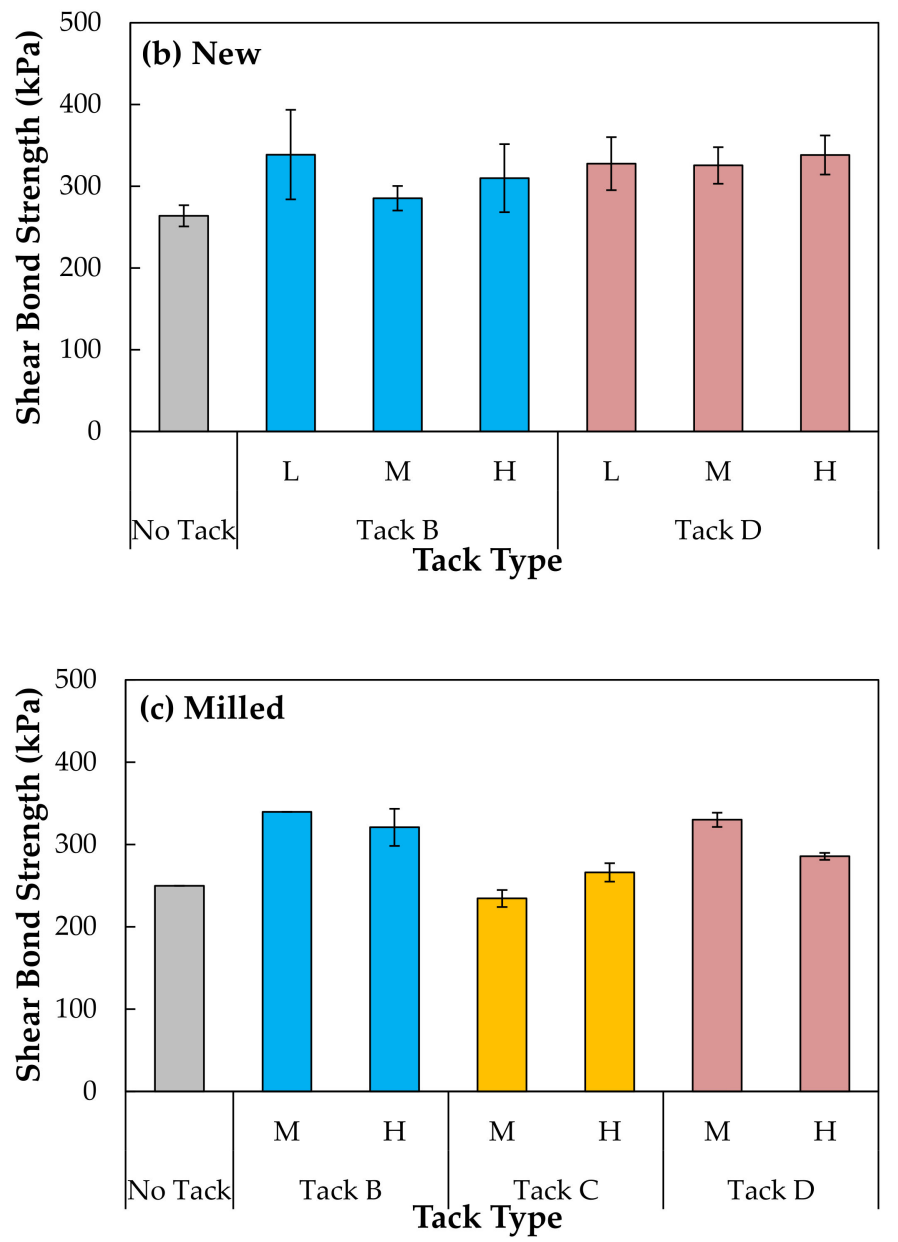

Figure 12. Effect of surface type, tack type, and residual tack rate on shear bond strength for field cores with different underlying layers in: (a) existing, (b) new, and (c) milled sections.

Figure 12c shows that the tack application on the milled layer slightly increased the shear strength. As explained previously in Figure 11c, some particle deposits on the groove of the bottom layer may inhibit the tacks from bonding at the interface. Thus, higher shear resistance can be achieved by eliminating dirt on the groove before tack treatment. In comparing the No Tack samples with the milled and existing substrates, the roughness of surface textures contributed to the higher shear resistance by aggregate interlocking. The milled layer showed the highest shear resistance at the moderate level of the residual tack rate, similar to the existing layer.

The results of the statistical analysis on interlayer shear resistance for each experiment are shown in Table 3. It is indicated that variables with the "** symbol have a significant effect on either shear strength or energy, and variables with the "**" symbol largely influence both shear bond strength and energy. The presence of a significant interaction of two variables means that one variable has a different impact on the shear bonding when considering different values of other variables. The results show that tack type did not significantly affect shear resistance for samples using a severely polished HMA substrate, compaction angle of $1.25^{\circ}$, overlay compacting temperature of $149^{\circ} \mathrm{C}$, and substrate temperature of $25^{\circ} \mathrm{C}$. However, tack type was a significant variable affecting both shear bond strength and energy in other experiments. In addition, the surface type and tack reactivation temperature made an important contribution to both shear bond strength and bond energy. The sensitivity of shear bond strength to tack type was different depending on the tack reactivation temperature and surface condition. The effect of compaction angle on shear bond energy, while statistically significant, was not as critical as that of tack type 
and temperature. Therefore, this variable was considered to have only a marginal effect on bond performance.

Table 3. Results of the statistical analysis of shear bond strength and energy.

\begin{tabular}{|c|c|c|c|c|c|c|c|c|c|}
\hline \multirow[b]{2}{*}{ Experiment } & \multirow{2}{*}{$\begin{array}{l}\text { Explanatory } \\
\text { Variable }\end{array}$} & \multicolumn{4}{|c|}{ Shear Bond Strength } & \multicolumn{4}{|c|}{ Shear Bond Energy } \\
\hline & & $\begin{array}{l}\text { Variable } \\
p \text {-Value }\end{array}$ & $\begin{array}{c}\text { Model } \\
p \text {-Value }\end{array}$ & $\begin{array}{c}\text { Model } \\
\mathbf{R}^{2}\end{array}$ & $\mathrm{COV}$ & $\begin{array}{l}\text { Variable } \\
p \text {-Value }\end{array}$ & $\begin{array}{c}\text { Model } \\
p \text {-Value }\end{array}$ & $\begin{array}{c}\text { Model } \\
\mathbf{R}^{2}\end{array}$ & $\mathrm{COV}^{1}$ \\
\hline \multicolumn{10}{|c|}{ Laboratory Compacted Samples } \\
\hline Tack type & Tack & $>0.05$ & - & - & - & 0.009 & 0.009 & 0.69 & 22.9 \\
\hline \multirow{3}{*}{$\begin{array}{l}\text { Substrate } \\
\text { type }\end{array}$} & Tack ** & $<0.001$ & \multirow{3}{*}{$<0.001$} & \multirow{3}{*}{0.97} & \multirow{3}{*}{7.3} & $<0.001$ & \multirow{3}{*}{$<0.001$} & \multirow{3}{*}{0.89} & \multirow{3}{*}{25.8} \\
\hline & Substrate $* *$ & $<0.001$ & & & & $<0.001$ & & & \\
\hline & Tack $\times$ substrate $*$ & $<0.001$ & & & & $>0.05$ & & & \\
\hline \multirow{3}{*}{$\begin{array}{l}\text { Tack } \\
\text { reactivation } \\
\text { temperature }\end{array}$} & Tack ** & $<0.001$ & \multirow{3}{*}{$<0.001$} & \multirow{3}{*}{0.83} & \multirow{3}{*}{8.5} & $<0.001$ & \multirow{3}{*}{$<0.001$} & \multirow{3}{*}{0.84} & \multirow{3}{*}{17.1} \\
\hline & Temp ** & $<0.001$ & & & & $<0.001$ & & & \\
\hline & Tack $\times$ temp * & $<0.001$ & & & & $>0.05$ & & & \\
\hline \multirow{3}{*}{$\begin{array}{c}\text { Compaction } \\
\text { effort }\end{array}$} & Comp. angle * & 0.03 & \multirow{3}{*}{$<0.001$} & \multirow{3}{*}{0.77} & \multirow{3}{*}{9.6} & $>0.05$ & \multirow{3}{*}{-} & \multirow{3}{*}{-} & \multirow{3}{*}{-} \\
\hline & Comp. angle $\times$ temp & $>0.05$ & & & & $>0.05$ & & & \\
\hline & Comp. angle $\times$ tack & $>0.05$ & & & & $>0.05$ & & & \\
\hline \multicolumn{10}{|c|}{ Field Cores } \\
\hline \multirow{6}{*}{$\begin{array}{l}\text { Residual } \\
\text { tack rate }\end{array}$} & Rate & $>0.05$ & \multirow{6}{*}{$<0.001$} & \multirow{6}{*}{0.68} & \multirow{6}{*}{14.9} & \multirow{6}{*}{-} & \multirow{6}{*}{-} & \multirow{6}{*}{-} & \\
\hline & Tack* & $<0.001$ & & & & & & & \\
\hline & Surface * & $<0.001$ & & & & & & & - \\
\hline & Rate $\times$ tack & $>0.05$ & & & & & & & \\
\hline & Rate $\times$ surface & $>0.05$ & & & & & & & \\
\hline & Tack $\times$ surface $*$ & $<0.001$ & & & & & & & \\
\hline
\end{tabular}

* indicates variables that have a significant effect on either shear bond strength or energy. ** indicates variables that have a significant effect on both shear bond strength and energy. $>0.05$ indicates a variable that is not significant and is removed from the model. " - " indicates a value not calculated. ${ }^{1}$ indicates a coefficient of variance.

In the field experiment, the effect of the residual tack rate on shear bond strength was not statistically significant. This consequence may be due to other surface conditions such as dirt and moisture, which were not considered in this study. In addition, the low number of replicates for tack rate may be another reason for the low significance level of tack rate on bonding. It can be concluded in the limited test results that the tack rate was a less influential variable for interlayer shear resistance than tack and surface type.

\section{Conclusions and Recommendations}

Trackless tacks play a prominent role in bonding layers under a thin overlay pavement without tracking, which is one of the concerns in using traditional tacks. However, there has been insufficient research on the characterization and performance evaluation of trackless tacks. Thus, the main objective of this study was to measure the bonding potential of different trackless tack materials. The experimental plan used in this study includes the DSR frequency sweep test and the direct shear test. The rheological properties of tack residual binders were identified in the DSR frequency sweep test. In addition, the shear bond strength and energy were measured as indicators of interlayer shear resistance. A variety of factors affecting the interface bonds were also evaluated using laboratory compacted samples and field cores. Based on these test results, the major findings are as follows.

1. Using the complex shear modulus obtained from the DSR frequency sweep test, the tack materials were classified into two groups based on their modulus values: control tack, Tack A, B, and C were classified in the soft-residue group, and Tack D and E were classified in the stiff-residue group. 
2. The laboratory samples exhibited high shear bond strength between 689 and $1379 \mathrm{kPa}$. Many laboratory samples did not fail at the interface, indicating that the interface bond was stronger than the internal strength of a substrate or overlay layer.

3. The bond strength of field cores was noticeably lower than that of laboratory compacted samples. In addition, interface failure occurred for all field cores. This consequence may be due to different fabrication methods (e.g., compaction and tack application) and different substrate conditions.

4. The factors that affect the bonding performance were evaluated through laboratory and field testing as follows:

(a) Tack type had a remarkable impact on shear resistance at lower tack reactivation temperatures. The laboratory samples applied with tack materials in the soft-residue group exhibited lower bond energy than ones in the stiff-residue group due to interface failure. The sensitivity of bond strength to tack type was different for field cores with the existing layer. The field cores applied with the tack in the stiff-residue group exhibited higher shear bond strength regardless of the surface type.

(b) Surface type had a significant effect on shear bond strength and bond energy. The laboratory samples with the HMA substrate layer had higher shear resistance than the ones with the concrete substrate. The field samples in the new HMA and milled sections had higher bond strengths than in the existing HMA sections.

(c) Compaction angle marginally affected the bond strength.

(d) Reactivation temperature had a significant impact on shear bond strength and bond energy. The shear bond energy increased with higher reactivation temperatures. The tack samples in the stiff-residue group had higher bond energy than the ones in the soft-residue group.

(e) Tack rate was a less influential factor in governing the shear bond strength than tack and surface type. In addition, the limited test results from the field samples and the low number of replicates for tack rate may not be enough to distinguish its impact on interlayer shear resistance.

In order to produce stronger bonds with tacks, the researchers suggest that the overlay mixture be compacted at higher ambient and mix temperatures. In addition, the substrate surface condition is an important factor affecting the bond strength. The tack application may not be required to construct the overlay over a new HMA as long as the compaction temperatures are high enough. When a thin lift overlay is constructed on heavily polished pavements, using an underseal having a stiffer residue or milling is recommended to ensure a better bond. Prior to tack application, it is necessary to remove excessive dirt deposited on the groove of the milled surface. When compared to surface type and tack type, the emphasis on the tack application rate can be reduced; however, the suggestion for optimum residual tack rates is to use a moderate level $\left(0.14-0.23 \mathrm{~L} / \mathrm{m}^{2}\right)$ in existing and milled layers, and a low level $\left(0.05-0.14 \mathrm{~L} / \mathrm{m}^{2}\right)$ in new layers. Importantly, the loss of a tack material due to its tracking property should be prevented.

Further research on the long-term bonding performance of trackless tack will be needed to set up criteria that suggests an acceptable interlayer resistance in the field.

Author Contributions: Conceptualization, M.S.S. and B.T.W.; methodology, A.Y.S. and B.T.W.; software, B.T.W.; validation, A.Y.S. and B.T.W.; formal analysis, A.Y.S.; investigation, A.Y.S.; resources, M.S.S. and B.T.W.; data curation, A.Y.S.; writing—original draft preparation, A.Y.S.; writing—review and editing, A.Y.S., M.S.S., and B.T.W.; visualization, A.Y.S.; supervision, M.S.S.; project administration, B.T.W.; funding acquisition, M.S.S. and B.T.W. All authors have read and agreed to the published version of the manuscript.

Funding: This research was funded by the Texas Department of Transportation (TxDOT), grant number 0-6814. The APC was not funded.

Institutional Review Board Statement: Not applicable. 
Informed Consent Statement: Not applicable.

Data Availability Statement: The data that support the findings of this study are available from the corresponding author, A.Y.S., upon reasonable request.

Conflicts of Interest: The authors declare no conflict of interest. The funders had no role in the design of the study; in the collection, analyses, or interpretation of data; in the writing of the manuscript, or in the decision to publish the results.

\section{References}

1. AASHTO. Pavement Preservation in the United States: Survey by the Lead States Team on Pavement Preservation; American Association of State Highway and Transportation Officials: Washington, DC, USA, 1999.

2. Chou, E.Y.J.; Datta, D.; Pulugurta, H. Effectiveness of Thin Hot Mix Asphalt Overlay on Pavement Ride and Condition Performance; FHWA/OH-2008/4; The University of Toledo: Toledo, OH, USA, 2008.

3. Mohammad, L.N.; Elseifi, M.A.; Bae, A.; Patel, N.; Button, J.; Scherocman, J.A. Optimization of Tack Coat for HMA Placement; NCHRP Report 712; National Cooperative Highway Research Program: Washington, DC, USA, 2012.

4. Muench, S.T.; Moomaw, T. De-Bonding of Hot Mix Asphalt Pavements in Washington State: An Initial Investigation; TNW 2008-10; Transportation Northwest Regional Center X (TransNow): Seattle, WA, USA, 2008.

5. Kruntcheva, M.R.; Collop, A.C.; Thom, N.H. Effect of Bond Condition on Flexible Pavement Performance. J. Transp. Eng. 2005, 131, 880-888. [CrossRef]

6. Al Hakim, B. An Improved Backcalculation Method to Predict Flexible Pavement Layers Moduli and Bonding Condition between Wearing Course and Base Course. Ph.D. Thesis, Liverpool John Moores University, Liverpool, UK, 1997.

7. Willis, J.R.; Timm, D.H. Forensic Investigation of a Rich-Bottom Pavement; NCAT Report 06-04; National Center for Asphalt Technology: Auburn, AL, USA, 2006.

8. Su, K.; Sun, L.; Hachiya, Y.; Maekawa, R. Analysis of Shear Stress in Asphalt Pavements under Actual Measured Tire-Pavement Contact Pressure. In Proceedings of the 6th International Conference on Pavement, Sapporo, Japan, 20-23 July 2008 ; pp. 11-18.

9. Kim, Y.R.; Tayebali, A.A.; Guddati, M.N.; Karshenas, A.; Cho, S.H. Surface Layer Bond Stresses and Strength; FHWA/NC/2013-04; North Carolina State University: Raleigh, NC, USA, 2015.

10. Gierhart, D.; Johnson, D.R. Tack Coat Specifications, Materials, and Construction Practices; National Cooperative Highway Research Program: Washington, DC, USA, 2018.

11. Roffe, J.-C.; Chaignon, F. Characterisation Tests on Bond Coats: Worldwide Study, Impact, Tests, Recommendations. In Proceedings of the 3rd International Conference on Bituminous Mixtures and Pavements, Thessaloniki, Greece, 21-22 November 2002.

12. Brown, S.; Brunton, J. The influence of Bonding Between Bituminous Layers. Highw. Transp. 1984, 31, 16-17.

13. Vaitkus, A.; Žilionienè, D.; Paulauskaitè, S.; Tuminienè, F.; Žiliūtè, L. Research and Assessment of Asphalt Layers Bonding. Balt. J. Road Bridge Eng. 2011, 6, 210-218. [CrossRef]

14. Seo, A.Y.; Sakhaeifar, M.S.; Wilson, B.T. Evaluating Tack Properties of Trackless Tack Coats through Dynamic Shear Rheometer. Transp. Res. Rec. 2017, 2632, 119-129. [CrossRef]

15. Lv, Q.; Bahia, H.U. Factors Affecting the Tracking Performance of Tack Coat Materials. Transp. Res. Rec. 2019, 2673, 355-364. [CrossRef]

16. Raposeiras, A.; Castro-Fresno, D.; Vega-Zamanillo, A.; Rodriguez-Hernandez, J. Test methods and Influential Factors for Analysis of Bonding between Bituminous Pavement Layers. Constr. Build. Mater. 2013, 43, 372-381. [CrossRef]

17. NCAT. Bonding of Layers is Critical to Good Performance. Asph. Technol. News 2015, 10-11.

18. West, R.C.; Zhang, J.; Moore, J. Evaluation of Bond Strength Between Pavement Layers; NCAT Report 05-08; National Center for Asphalt Technology: Auburn, AL, USA, 2005.

19. Raab, C.; Partl, M.N. Investigation into a Long-Term Interlayer Bonding of Asphalt Pavements. Balt. J. Road Bridge Eng. 2008, 3 , 65-70. [CrossRef]

20. McGhee, K.K.; Clark, T.M. Bond Expectations for Milled Surfaces and Typical Tack Coat Materials Used in Virginia; VTRC 09-R21; Virginia Transportation Research Council: Charlottesville, VA, USA, 2009.

21. Uzan, J.; Livneh, M.; Eshed, Y. Investigation of Adhesion Properties between Asphaltic-Concrete Layers. In Proceedings of the Association of Asphalt Paving Technologists, Lake Buena Vista, FL, USA, 13-15 February 1978; pp. 495-521.

22. Santagata, E.; Canestrari, F. Tensile and Shear Tests of Interfaces in Asphalt Mixes: A New Prospective on Their Failure Criteria. In Proceedings of the 2nd International Symposium on Highway Surfacing, Newtownabbey, UK, 27-28 January 1994.

23. Romanoschi, S.; Metcalf, J. Characterization of Asphalt Concrete Layer Interfaces. Transp. Res. Rec. J. Transp. Res. Board 2001, 1778, 132-139. [CrossRef]

24. Hakimzadeh, S.; Kebede, N.A.; Buttlar, W.G.; Ahmed, S.; Exline, M. Development of Fracture-Energy Based Interface Bond Test for Asphalt Concrete. Road Mater. Pavement Des. 2012, 13, 76-87. [CrossRef]

25. Al-Qadi, I.L.; Hasiba, K.I.; Salinas Cortina, A.; Ozer, H.; Leng, Z.; Parish, D.C.; Worsfold, S.J. Best Practices for Implementation of Tack Coat: Part I-Laboratory Study; FHWA-ICT-12-004; Illinois Center for Transportation: Rantoul, IL, USA, 2012.

26. Mohammad, L.; Bae, A.; Elseifi, M.; Button, J.; Patel, N. Effects of Pavement Surface Type and Sample Preparation Method on Tack Coat Interface Shear Strength. Transp. Res. Rec. J. Transp. Res. Board 2010, 2180, 93-101. [CrossRef] 
27. Tran, N.; Willis, R.; Julian, G. Refinement of the Bond Strength Procedure and Investigation of a Specification; NCAT Report 12-04; National Center for Asphalt Technology: Auburn, AL, USA, 2012.

28. Zhao, H.; Cao, J.; Zheng, Y. Investigation of the Interface Bonding between Concrete Slab and Asphalt Overlay. Road Mater. Pavement Des. 2017, 18, 109-118. [CrossRef]

29. Amelian, S.; Kim, Y.-R. Evaluation of Tack Coating Practices for Asphalt Overlays in Nebraska; SPR-P1(16) M039; Nebraska Transportation Center: Lincoln, NE, USA, 2017.

30. Seo, A.Y.; Sakhaeifar, M.S.; Wilson, B.T. Chemical-Mechanical Interaction of Non-Tracking Tack Coat and Aggregate on Bond Strength. In Proceedings of the Airfield and Highway Pavements 2015, Miami, FL, USA, 7-10 June 2015; pp. $191-202$.

31. Banihashemrad, A.; Sakhaeifar, M.; Wilson, B.; Seo, A.Y. Investigation of the Significant Factors Affecting the Shear Bond Strength in the Field. In Proceedings of the Transportation Research Board 98th Annual Meeting, Washington, DC, USA, 13-17 January 2019.

32. Chen, Y.; Tebaldi, G.; Roque, R.; Lopp, G. Effects of Trackless Tack Interface on Pavement Top-Down Cracking Performance. Procedia-Soc. Behav. Sci. 2012, 53, 432-439. [CrossRef]

33. Clark, T.M.; Rorrer, T.M.; McGhee, K.K. Trackless Tack Coat Materials: A Laboratory Evaluation for Performance Acceptance; Virginia Center for Transportation Innovation and Research: Charlottesville, VA, USA, 2012.

34. Petersen, J.C.; Robertson, R.E.; Branthaver, J.F.; Harnsberger, P.M.; Duvall, J.J.; Kim, S.S. Binder Characterization and Evaluation, Volume 4: Test Methods; SHRP-A-370; Strategic Highway Research Program, National Research Council: Washington, DC, USA, 1994.

35. Lorenz, B.; Pyckhout-Hintzen, W.; Persson, B. Master Curve of Viscoelastic Solid: Using Causality to Determine the Optimal Shifting Procedure, and to Test the Accuracy of Measured Data. Polymer 2014, 55, 565-571. [CrossRef]

36. Airey, G.D. Use of Black Diagrams to Identify Inconsistencies in Rheological Data. Road Mater. Pavement Des. 2002, 3, 403-424. [CrossRef]

37. Pamplona, T.F.; de Amoni, B.C.; de Alencar, A.E.V.; Lima, A.P.D.; Ricardo, N.M.; Soares, J.B.; de Soares, S.A. Asphalt Binders Modified by SBS and SBS/Nanoclays: Effect on Rheological Properties. J. Braz. Chem. Soc. 2012, 23, 639-647. [CrossRef] 